\title{
Educaçáo inclusiva: do paradigma da igualdade para o paradigma da diversidade
}

\author{
Claudia S. G. Barreto* \\ Marlene Barbosa de Freitas Reis**
}

\section{Resumo}

Este artigo apresenta reflexóes sobre o tema educação inclusiva no contexto educacional, bem como os desafios ainda presentes na formação de professores para lidar com a diversidade nas salas de aula. $\mathrm{O}$ trabalho inicia-se com uma breve abordagem de termos relevantes sobre a concepção de educaçáo inclusiva, a fim de situar o leitor nesse "novo" paradigma de educação, que pensa o contexto educacional como espaço de oportunidades de debates, de estilos e ritmos de aprendizagens diferentes. Por isso, abarca as concepçóes da educação inclusiva que prima para o reconhecimento do outro, para o diálogo entre os diferentes grupos sociais e culturais e para o favorecimento da construçáo de um projeto comum, no qual as diferenças sejam dialeticamente incluídas. Em seguida, é realizada uma análise acerca das políticas públicas que norteiam as práticas pedagógicas e a formaçáo de professores para práticas inclusivas. Em última análise, o artigo aponta perspectivas para a efetivação de uma educação inclusiva por meio da valorização do profissional da educação e do respeito à diversidade humana. Nesse contexto, discutem-se os atuais projetos de formação docente que se apresentam em uma estrutura aligeirada do conhecimento, deixando de aprofundar conhecimentos que possibilitam ao docente vislumbrar um contexto mais amplo de conteúdos voltados para a grande diversidade que constitui o processo educacional numa perspectiva inclusiva.

Palavras-chave: educação inclusiva, práticas educacionais, diversidade, políticas públicas.

Inclusive education: from the equality paradigm to the diversity paradigm

\section{Abstract}

This article presents reflections on the theme of inclusive education in the educational context, and the challenges for teacher formation in dealing with diversity in the class-

* Professora assistente do Centro de Ensino e Pesquisa Aplicada à Educaçấo (Cepae), da Universidade Federal de Goiás (UFG). E-mail: claudiabarreto.ufg@gmail.com.

** Pedagoga, professora de Estágio no curso de Pedagogia da Universidade Estadual de Goiás (UEG), em Inhumas-GO. Doutoranda em Políticas Públicas, Estratégias e Desenvolvimento pela Universidade Federal do Rio de Janeiro (UFRJ/UEG), mestre em Educação, especialista em Planejamento Educacional.E-mail: marlenebfreis@hotmail.com. 
room. The study begins with a brief presentation of important terms on the conception of inclusive education, in order to situate the reader in this "new" educational paradigm, which sees the educational context as an opportune space for debate, different learning styles and rhythms. It incorporates the conceptions of inclusive education which prioritizes recognition of the other, dialogue between different social and cultural groups, fosters the building of a common project, in which differences are dialectically included. It then analyzes policies which underline pedagogical practices and the formation of teachers for inclusive practices. Finally, the article points to perspectives for bringing about inclusive education through the valorization of education professionals and respect for human diversity. In this context it discusses current projects for teacher formation presented in short courses, which do not provide in-depth knowledge for the teacher to visualize the broader context of content on greater diversity which constitutes the educational process from an inclusive perspective.

Keywords: inclusive education, educational practices, diversity, public policies.

\section{Introdução}

Acolher a diversidade de indivíduos e contar com professores preparados para a escola inclusiva é um dos grandes desafios da educação na atualidade. Frente a esse desafio, entende-se a urgência e a necessidade de romper com os velhos paradigmas de uma educação padronizada e com a visão homogênea de alunos classificados segundo padróes de normalidade. Ou seja, romper com o modelo de educação que segrega e exclui aqueles que não se enquadram nos padróes estabelecidos pela sociedade.

Contudo, temos observado e testemunhado, sobretudo na última década, grandes avanços na luta pela ruptura da "pedagogia da igualdade" em favor da "pedagogia da diversidade", reconhecendo que a inclusão no ambiente educacional é essencial para o fortalecimento da dignidade e exercício dos direitos humanos. Nesse contexto, considera-se, neste trabalho, educação para a diversidade na perspectiva inclusiva, a garantia de acesso, de permanência e, sobretudo, a garantia de aprendizagem a todos os educandos, de forma indistinta.

O movimento denominado inclusão vem influenciando a formulação e implementação de políticas públicas, bem como vem desafiando a todos a pensar numa educação que não só reconheça as diferenças, mas que faça valer os princípios dos direitos humanos. No Brasil, muito já se avançou, mas há ainda vários desafios a vencer e outros tantos a conquistar, principalmente, no campo educacional, nos seus diferentes níveis e modalidades. 
A expressão diversidade tem sido frequentemente empregada com múltiplos significados, tanto na área social, quanto física, emocional, ambiental, e, sobretudo, na cultural. Dada a sua amplitude e complexidade conceitual, vale destacar que, neste estudo, diversidade é tratada como variedade e convivivência de ideias diferentes, de pessoas diferentes no mesmo espaço onde o paradigma da heterogeneidade sobrepóe o da homogeneidade. Por isso, abarca as concepçóes da educação inclusiva.

Essa concepção incita pensar o espaço educacional como espaço de oportunidades de debates, de estilos e ritmos de aprendizagens diferentes, por isso envolve as concepçóes da educação inclusiva, isto é, uma educação que prima para o reconhecimento do outro, para o diálogo entre os diferentes grupos sociais e culturais, para o favorecimento da construção de um projeto comum, pelo qual as diferenças sejam dialeticamente incluídas (CANDAU, 2008). Essa é, portanto, a concepção de inclusão e diversidade adotada neste trabalho.

\section{Concepçóes de inclusão e contextualização}

Por vivermos em uma cultura em que prevalece o domínio da linguagem e da escrita como forma de poder, os que náo alcançam essa competência perdem espaço e são excluídos dos processos considerados mais significativos da cultura.

A primeira questão que podemos refletir é sobre as práticas educativas e por que muitas delas, de alguma maneira, excluem o educando que apresenta um desenvolvimento diferenciado no cotidiano escolar. $\mathrm{O}$ que se tem discutido é que trabalhar com as diferentes formas de aprender passa, essencialmente, pela formação do educador, ou seja, não somos "formados" para ensinar alunos que aprendem de forma diferente. Embora não desejemos excluir ninguém, o processo de exclusão apresenta-se de maneira cada vez mais evidente em nosso contexto escolar.

Para Sawaia (2002), estar excluído é estar fora de algo por uma decisão que não foi tomada pelo próprio sujeito. A exclusão é determinada por outrem, de maneira individual ou coletiva. A partir dessas concepçóes, portanto, busca-se o sentido de exclusão para os alunos considerados, muitas vezes, como fracassados na escola.

Ao refletirmos sobre esse processo, buscamos repensar como se dá a construção do conhecimento nas diversas áreas do ensino, a partir do contexto 
da diversidade. Dificilmente contemplaremos as diferentes formas de aprender de nossos alunos a partir de um enfoque determinista e padronizado, centrando-se somente no resultado da aprendizagem, ignorando o processo no qual ela se deu e também o modo como o educando construiu suas significaçôes. Para Vygotsky (1998), esse trajeto percorrido pelo aluno é relevante para se compreender seu desenvolvimento. Ele considera, de maneira especial, as diversas relaçóes cognitivo-afetivas envolvidas nessa construção.

Ao apresentar um desenvolvimento diferenciado e não corresponder a um ideal de aprendizagem, o aluno, geralmente, é considerado incapaz e seu tempo de aprender não é respeitado. Assim, são transformadas as formas diferenciadas de aprender em deficiência de aprendizagem. O diferente torna-se, assim, anormal.

$\mathrm{O}$ respeito às diferenças individuais e a grande diversidade de formas de aprendizagem presentes no contexto escolar consideram a singularidade de cada um, privilegiando suas competências. A competência é entendida como capacidade de articular um conjunto de recursos próprios, que são as experiências e habilidades já adquiridas para resolver as mais variadas situaçôes.

Pela forma de se trabalhar o conhecimento, de valorizar os saberes trazidos pelos alunos, pela qualidade das relaçôes entre professor-aluno, aluno-aluno e pela realidade de vida do educando e suas possibilidades, desenvolve-se um processo de sucessos ou de fracassos. É importante perceber que cada aluno tem desempenhos muito diferentes na relação com os objetos de conhecimento e a prática escolar tem que buscar reconhecer essa diversidade para assegurar respeito aos diferentes sujeitos e possibilitar avanços em suas aprendizagens.

O aluno considerado como um sujeito com necessidades especiais também é capaz de avançar em seu processo de aprendizagem, porém de forma particular, pois ele é, na verdade, um sujeito com um desenvolvimento diferenciado, sua personalidade não apresenta só funções subdesenvolvidas, ela é qualitativamente diferente. A personalidade desenvolve-se com leis e tendências próprias e particulares e ela não é decidida pela deficiência, mas pelas consequências sociais dela (VYGOTSKY, 1993). É na relação com o outro que o aluno passa a perceber suas limitaçóes, e a forma como o outro a significa pode levá-lo a uma situação de desenvolvimento ou de retrocesso.

A escola como produtora de igualdades prioriza a homogeneidade e exclui os que se diferenciam. Essa é a opinião de Figueiredo (2002), o qual ressalta, ainda, que é impossível não considerar que as diferenças são 
inerentes ao gênero humano. Elas nos fazem distintos, sem possibilidades de repetição, pois o humano é essencialmente singular pelas suas diferenças e tais dessemelhanças confirmam nossa unicidade e nos fazem também especiais aos olhos do outro. Por outro lado, se as diferenças nos tornam singulares, são as similitudes que nos aproximam como elementos do grupo social, pois as semelhanças vivenciadas na forma mais intensa do humano é que nos permitem gerar o sentimento de pertença.

É necessário que se compreenda que as dificuldades que o educando apresenta em seu processo de escolarização podem ter como causa uma estrutura curricular padronizada e totalmente impessoal, que, por sua vez, o impede de trabalhar com a grande diversidade de formas de aprendizagem presentes nesse contexto. Acontece que alguns alunos ainda não têm condiçóes de fazer relaçóes e construir seus conhecimentos sozinhos e a mediação do professor e dos demais colegas da sala é fundamental para seu aprendizado.

Embora tenham ocorrido avanços na educação brasileira, ainda há fortes tendências à padronizaçáo do ato de educar, que exige aprendizado na mesma medida. Em muitos casos, a escola náo compreende as diferentes formas utilizadas pela criança para elaborar seu aprendizado, desprezando os conhecimentos que ela traz e exigindo dela conceituaçóes que ainda não é capaz de elaborar. Nessa situação, a criança é geralmente rotulada como não competente e isso é reforçado quando a escola a encaminha para uma avaliação psicológica por dificuldades de aprendizagem. Numa prática tradicional, ela é submetida a testes psicológicos que, de acordo com Daniels (1993), não oferecem subsídios para a compreensão de aspectos como o processo de ensino e aprendizagem, a sua história de vida, nem tampouco acerca de suas concepções sobre leitura, escrita e número. Por mais modernos que sejam esses testes, eles julgam a existência de características fixas e mensuráveis no indivíduo, que se desenvolvem de maneira regular e previsível. Esses testes implicam uma concepção reducionista sobre o que esperar das crianças em idades e situaçóes variadas (BEZERRA, 2003).

A avaliação psicológica e a pedagógica são processos que devem caminhar juntos, de forma individualizada, jamais padronizada, e necessita contemplar os vários aspectos que envolvem o aluno em suas diferentes vivências.

As relaçóes que se formam no processo de desenvolvimento tornam-se mais significativas quando o educando estabelece ligação com suas vivências, contextualiza o saber e constrói instrumentos para criar e recriar sua realidade - quando, assim, se torna capaz de compreender e lidar com as diferenças 
individuais e sociais presentes no seu cotidiano. Desse modo, o que deve ser enfatizado são suas potencialidades e não as suas deficiências.

\section{Fundamentos legais que respaldam a educação inclusiva}

A educação inclusiva no contexto educacional é uma abordagem que procura responder às necessidades de aprendizagem de todas as crianças, jovens e adultos, com foco específico para aqueles que são vulneráveis à marginalização e à exclusão.

Nessa perspectiva, entendemos que o desenvolvimento de sistemas educacionais inclusivos, nos quais as escolas e professores devem acolher todas as crianças, jovens e adultos, independentemente de suas condiçóes físicas, intelectuais, sociais, emocionais, linguísticas e outras, representa uma possibilidade de combate à exclusão e de responder às especificidades dos alunos.

Assim, o reconhecimento dessas diferenças tem sido fortemente respaldado por documentos legais que têm direcionado ao reconhecimento e à valorização dos direitos humanos em todas as suas dimensóes.

A Declaração Universal dos Direitos Humanos promulgada em 1948 pela Organização das nações Unidas representa um avanço significativo na revisão dos direitos humanos e na garantia legal do combate à discriminação, ou seja, representa uma política pública de proteção aos grupos sociais menos favorecidos, restituindo-lhes os direitos básicos de sobrevivência com melhor qualidade de vida.

Já no seu artigo $1^{\circ}$, a Declaração reconhece que "todos os seres humanos nascem livres e iguais, em dignidade e direitos. São dotados de razão e consciência e devem agir em relação uns aos outros com espírito de fraternidade". Isso significa que, independentemente de condiçóes físicas ou outra qualquer, o direito à dignidade humana deve ser respeitado sem nenhuma distinção de raça, cor, sexo, língua, religião, etc. Nesse sentido, "todos são iguais perante a lei e, sem distinção, têm direito a igual proteção da lei”, conforme destaca o art. $7^{\circ}$. Esse aspecto legal assegura às crianças, jovens e adultos um tratamento pautado na ética e no respeito às diferenças, em que a participação social está intimamente relacionada ao exercício pleno de cidadania.

Como podemos observar, o direito ao desenvolvimento pleno, conforme destacado na declaração, não tem sido efetivado nas práticas sociais, pois as desigualdades econômicas, sociais e culturais representam grandes 
desafios para a perspectiva inclusiva. Contudo, continuou ganhando destaque nos fundamentos legais.

A proposta de uma abordagem inclusiva no campo da educação vem obtendo avanços consideráveis, que se tornaram mais significativos após a Conferência Mundial sobre Necessidades Educativas Especiais (1994), na Espanha, quando foi elaborada a Declaração de Salamanca sobre os princípios, políticas e práticas na área das necessidades educativas especiais.

A partir dessa conferência, tem-se disseminado os conceitos de inclusão e de educação inclusiva, evidenciando uma preocupação com todos aqueles que se encontram excluídos do processo educacional.

Em estudos sobre as abordagens elencadas na conferência supracitada, Reis (2006, p. 30) expressa e reforça que o conceito de necessidades educacionais especiais amplia-se e passa a incluir, além das crianças portadoras de deficiências, aquelas que experimentam dificuldades temporárias, que repetem continuamente os anos escolares, que não têm onde morar, que trabalham para ajudar no sustento da família, que sofrem de extrema pobreza, ou que, simplesmente, estão fora da escola, por qualquer motivo.

Portanto, a inclusão não se refere apenas aos alunos que apresentam algum tipo de deficiência específica, mas a todos que também possuem alguma dificuldade para aprender. Essa concepção consolida a proposta de uma educação para todos e não para alguns, constituindo-se num dos mais importantes avanços da perspectiva inclusiva nos sistemas regulares de ensino.

Estudiosos sobre a temática da inclusão, dentre eles Mantoan (2006), alertam sobre um desafio que se coloca e que tende a nos desviar do caminho a percorrer na busca de uma mudança efetiva de propostas e práticas inclusivas, que é a visão distorcida e/ou reducionista que envolve esse tema. Um bom exemplo é o da não diferenciação entre o processo de integração escolar e o processo de inclusão escolar, que acaba por reforçar concepçóes do paradigma tradicional de educação.

Embora, por muitas vezes, os termos integração e inclusão sejam utilizados como sinônimos, é importante ressaltar que há uma diferença real de valores e de práticas entre eles.

O termo integração, como aborda Mantoan (2006, p.18), refere-se à inserção de alunos com deficiência nas escolas comuns, mas os alunos é que têm de mudar para se adaptar às suas exigências. Esse aspecto reforça a concepção segregacionista da educação, uma vez que não "cabe" às escolas a responsabilidade de mudanças e adequaçóes necessárias ao processo inclusivo. 
Em outra esfera, está a concepção de inclusão escolar, que é incompatível com a integração, já que a abordagem de Mantoan (2006, p.19) "prevê a inserção escolar de forma radical, completa e sistemática. Todos os alunos, sem exceção, devem frequentar as salas de aula de ensino regular”. Nestes termos, pensar a inclusão é fazer um movimento que busca repensar a escola, para que deixe de ser a escola da homogeneidade e passe a ser a escola da heterogeneidade, para que a escola da discriminação e segregação dê lugar à escola aberta a todos.

Sendo assim, uma escola inclusiva deve ser o modelo da escola de qualidade, promovendo o acesso, a permanência e o sucesso dos alunos, independentemente de suas necessidades e possibilidades de aprendizagem, uma vez que é a escola a responsável por formar o cidadão "e a ele deve ser dada a oportunidade de obter e manter um nível aceitável de aprendizagem” (BRASIL, 1994, p. 7).

De forma bem generalizada, em todos os países a legislação tem sido vista como um dos instrumentos mais importantes para assegurar os direitos humanos e eliminar o processo discriminatório e excludente, o que tem desencadeado impactos nas políticas públicas brasileiras e, de forma bem específica, nas políticas educacionais nas últimas duas décadas.

A atual Lei de Diretrizes e Bases da Educação Nacional (LDBEN), Lei n. 9.394/96, foi aprovada no governo de Fernando Henrique Cardoso e do então ministro da Educação Paulo Renato, em 20 de dezembro de 1996, e fundamenta o direito universal de uma incipiente "educação para todos" em escolas regulares de ensino.

Seu artigo 59 preconiza que os sistemas de ensino assegurarão aos educandos com necessidades especiais currículos, métodos, recursos e organização específicos para atender às suas necessidades. Assegura, ainda, em seu inciso II, o caráter de terminalidade específica àqueles que, por algum motivo, não conseguirem o nível exigido para a conclusão do ensino fundamental, em virtude de suas deficiências, bem como a aceleraçáo de estudos para os superdotados, a fim de que concluam em menor tempo possível o programa escolar.

A LDBEN/96 é clara ao implementar diretrizes para que o poder público se comprometa a adotar medidas de caráter inclusivo na política educacional brasileira. Esse marco normativo sinaliza uma conquista nos princípios básicos da educação pública no sentido de propiciar um amplo debate no campo das reformas educacionais e no fortalecimento de enfoques mais humanistas e menos excludentes. 
A Constituição Federal promulgada em 05 de outubro de 1988, uma das mais importantes reformas brasileiras pós década de 1980, traz em seu art. 205 que a educação, sendo um direito de todos e dever do Estado e da família, será promovida e incentivada com a colaboração da sociedade, visando ao pleno desenvolvimento da pessoa, seu preparo para o exercício da cidadania e sua qualificação para o trabalho. Complementa, no artigo 2008, inciso III, o dever do Estado com a educação, garantindo atendimento educacional especializado aos portadores de deficiência, preferencialmente na rede regular de ensino.

Pautada no princípio da descentralização, a Constituição delega aos municípios autonomia política para tomar decisóes e implantar recursos e processos necessários para colocar em prática suas determinaçóes. Nesse sentido, também garante o direito de escola para todos a partir do atendimento de um conjunto de valores e princípios que garantam a melhoria da qualidade de vida de seus cidadãos.

Essas duas leis que regulamentam a política educacional brasileira sustentam outras diretrizes que dão movimento ao campo da educação inclusiva, como o Plano Nacional de Educação, que se encontra em análise e votação no Congresso Nacional. A proposta do novo PNE (2011-2020), denominado II PNE, pode ser caracterizada como uma política pública educacional de muita expressividade e que também marca a defesa de uma escola democrática, plural e aberta às diferenças. Por isso, merece destaque e traz à tona o tratamento dado à educação inclusiva em sua meta 4 , e seus respectivos desdobramentos, chamados de 06 (seis) estratégias (BRASIL, 2011, p. 7).

Meta 4: Universalizar, para a população de 4 a 17 anos, o atendimento escolar aos estudantes com deficiência, transtornos globais do desenvolvimento e altas habilidades ou superdotação na rede regular de ensino. Estratégias:

4.1) Contabilizar, para fins do repasse do Fundo de Manutenção e Desenvolvimento da Educação Básica e de Valorização dos Profissionais da Educação - FUNDEB, as matrículas dos estudantes da educação regular da rede pública que recebem atendimento educacional especializado complementar, sem prejuízo do cômputo dessas matrículas na educação básica regular.

4.2) Implantar salas de recursos multifuncionais e fomentar a formação continuada de professores para o atendimento educacional especializado complementar, nas escolas urbanas e rurais.

4.3) Ampliar a oferta do atendimento educacional especializado complementar aos estudantes matriculados na rede pública de ensino regular. 
4.4) Manter e aprofundar programa nacional de acessibilidade nas escolas públicas para adequação arquitetônica, oferta de transporte acessível, disponibilização de material didático acessível e recursos de tecnologia assistiva, e oferta da educação bilíngüe em língua portuguesa e Língua Brasileira de Sinais - LIBRAS.

4.5) Fomentar a educação inclusiva, promovendo a articulação entre o ensino regular e o atendimento educacional especializado complementar ofertado em salas de recursos multifuncionais da própria escola ou em instituiçóes especializadas.

4.6) Fortalecer o acompanhamento e o monitoramento do acesso à escola por parte dos beneficiários do benefício de prestação continuada, de maneira a garantir a ampliação do atendimento aos estudantes com deficiência na rede pública regular de ensino.

O fato de o II PNE (2011-2020) contemplar a educação inclusiva na meta 4, acima mencionada, revela a necessidade de iniciativas e investimentos nessa modalidade de ensino, já que o tema da inclusão tem sido recorrente nos marcos normativos da educaçáo brasileira. Contudo, vale destacar que esse discurso eivado de preocupação com uma política inclusivista ainda não é suficiente para superar as desigualdades sociais exacerbadas pelo processo histórico de exclusáo social gestado e consolidado pelo sistema capitalista até então por nós conhecido.

Recentemente, o PNE (2011-2020) foi objeto de discussão e reflexão proporcionado pelo III Seminário de Educação Brasileira promovido pelo Centro de Estudos Educação e Sociedade, na Universidade Estadual de Campinas (Unicamp), de 28 de fevereiro a 02 de março de 2011. Iniciativas como essa reforçam a necessidade de articulação da sociedade civil para o exercício de se pensar coletivamente em propostas alavancadoras de uma educação fundada nos princípios democráticos e inclusivos.

\section{Perspectivas}

O investimento efetivo na formação e qualificação de profissionais da educação torna-se essencial quando se propóe uma educação inclusiva que atenda a todos sem exceção. Tratando-se de formação inicial e/ou continuada voltada para a inclusão educacional, precisamos alvejar, além de uma simples especialização, cursos de curta duração na atualização de conhecimentos pedagógicos. Educar, na perspectiva inclusiva, supóe dar um novo 
significado ao papel do professor e sua atuação no contexto educacional; é desconstruir todo um paradigma de educação pautado na homogeneização e normalidade para privilegiar um novo projeto de educação para todos.

A necessidade emergente desse novo projeto ainda não tornou-se prioridade para os que elaboram as políticas públicas de educação e, por isso, a formação de professores e outros profissionais para a educação inclusiva ainda continua sendo proposta em níveis meramente superficiais, o que impede a transformação da escola na abertura incondicional à diversidade e, consequentemente, a um ensino de qualidade (MANTOAN, 2006).

Para Michels (2006), o governo oferece uma formação de professores aligeirada e com perspectiva utilitária por focar somente na prática docente. Tal política de formação não possibilita ao educador enxergar os mecanismos de exclusão no interior da escola, pelo contrário, com o discurso da inclusão e a necessidade de aceitar as diferenças, perpetua o processo de exclusão.

Dessa forma, um dos grandes desafios para professores e profissionais da educação é compreender toda uma gama de complexidades que antecipa a organizaçáo do aprender e, consequentemente, o desenvolvimento individual articulado nos diferentes espaços (BEZERRA, 2004).

\section{Consideraçóes finais}

A par das reflexóes tecidas na estrutura deste artigo, pode-se considerar que a atual visão de uma escola inclusiva na perspectiva da diversidade corresponde a uma mudança da visão tradicional de escola, do velho paradigma homogêneo, bem como da maneira como as pessoas sempre foram identificadas pela sociedade a partir dos binômios exclusão-inclusão, normal-anormal, perfeito-imperfeito, enfim, pelos estereótipos da seleção e classificação.

Para se trabalhar com a diversidade no contexto educacional é preciso considerar a singularidade de cada um, privilegiando suas competências. A competência é entendida como capacidade de articular um conjunto de recursos próprios, que são as experiências e habilidades já adquiridas para resolver as mais variadas situaçóes.

$\mathrm{O}$ crescimento intelectual do aluno só acontece à medida que ele cresce também como sujeito. A ideia de sujeito discutida neste estudo é inspirada nos trabalhos de Rey (2003), o qual coloca o sujeito como social e histórico. O caráter social atua como elemento produtor de sentido em suas 
mais diversas relaçóes e na história de vida desse sujeito, uma história que não se apresenta de forma passiva, mas, sim, como uma configuração geradora de sentidos que estão em constante relação com os sentidos produzidos no curso de suas experiências.

A estrutura educacional deve ser repensada no sentido de rever sua organização e concepçóes fundamentais, como: conteúdos curriculares vinculados à realidade histórico-cultural dos alunos; o sistema de avaliação como elemento facilitador e promotor de aprendizagens; a valorizaçáo do educador como profissional competente para trabalhar esse conteúdo de forma contextualizada e significativa; a qualidade das relaçóes que se estabelecem no espaço escolar, respeitando as diferenças e o lugar da emoçáo nessas interaçôes, haja vista que a organização conceitual do lugar da emoção tem estado ausente das teorias de aprendizagem.

Sempre se priorizou o estudo da razão e das funções intelectuais, principalmente na ciência, pois muitos teóricos acreditam que os afetos deformam o conhecimento objetivo (BOCK, 2001). Tal concepção contraria os fundamentos da abordagem inclusiva, que valoriza o sujeito em seus múltiplos aspectos e, de forma especial, o papel da emoção e da afetividade na relação professor e aluno.

Dessa forma, para que se efetive essa perspectiva de inclusão, é necessário que as pessoas envolvidas no processo persistam, aceitem os desafios, acreditem que é possível e ampliem as açôes empreendidas. Só assim a educação inclusiva deixará de ser mera formalização, um aspecto garantido pela legislaçáo e por documentos educacionais - como ainda é vista por muitos. Passará, desse modo, a ser cada vez mais real nas escolas brasileiras e na sociedade (REIS e SILVA, 2011).

\section{Referências}

BEZERRA, C. S. G. B. Aprendizagem e subjetividade: Um estudo de caso baseado na perspectiva histórico-cultural. Revista Fórum Crítico da Educação, Rio de Janeiro, ISEP, v. 8, p. 43. 2003.

O sentido subjetivo do aprender. 2004. Dissertação (Mestrado) Pontifícia Universidade Católica de Goiás, Goiânia, 2004.

BOCK, A. M. B. Psicologia sócio-histórica. SP: Cortez, 2001. 
BRASIL. Declaração de Salamanca e linha de ação sobre necessidades educativas especiais. 1994. Disponível em: <http://portal.mec.gov.br/seesp/arquivos/pdf/salamanca.pdf>. Acesso em: 30 mar. 2011.

. Política Educacional Especial na Perspectiva da Educação Inclusiva. 2007. Disponível em: < http://portal.mec.gov.br/seesp/arquivos/pdf/politica.pdf>. Acesso em: 30 mar. 2011.

. Constituição da República Federativa do Brasil. Brasília: Imprensa Oficial, 1988.

. Plano Nacional de Educação 2011-2020. 2011. (Em tramitação)

CANDAU, V. M. Multiculturalismo e educação: desafios para a prática pedagógica. In: MOREIRA, A. F.; CANDAU, V. M. (Orgs). Multiculturalismo e educação: desafios para a prática pedagógica. 2. ed. Petrópolis, RJ: Vozes, 2008. p. 13-37.

DANIELS, H. Vygotsky em foco: pressupostos e desdobramentos. Campinas: Papirus, 1993.

FIGUEIREDO, R. V. Políticas de inclusão: escola-gestão da aprendizagem na diversidade. In: Políticas organizativas e curriculares, educação inclusiva e formação de professores. Rio de Janeiro: DP\&A, 2002.

MANTOAN, M. T. E. Inclusão escolar: o que é? Por quê? Como fazer? São Paulo: Moderna, 2006.

MICHELS, M. H. Gestão, formação docente e inclusão: eixos da reforma educacional brasileira que atribuem contornos à organização escolar. Revista Brasileira de Educação, v. 11, n. 33, set./dez. 2006.

REIS, M. B. F. Educação inclusiva: limites e perspectivas. Goiânia: Deescubra, 2006.

; SILVA, L. R. S. Educaçấo Inclusiva: o desafio da formação de professores. In: REVELLI. Revista de educação, linguagem e literatura da UEG-Inhumas, ISSN 1984-6576, v. 3, n. 1, p. 07-17, mar. 2011.

REY, F. L. G. Sujeito e subjetividade. São Paulo: Thomson, 2003. 
32 Polyphonía, v. 22/1, jan./jun. 2011

SAWAYA, B. B. Dialética exclusão/inclusão. Reflexóes metodológicas e relatos de pesquisas na perspectiva da psicologia social crítica. São Paulo: Cabral Editora Universitária, 2002.

VYGOTSKY, L. S. The collected works of L. S. Vygotsky The fundamentals of defectology. New York: Plenum Press, 1993. . A formação social da mente. São Paulo: Martins Fontes, 1998.

Recebido em: 30 nov. 2011.

Aceito em: 10 abr. 2012. 